\title{
Vaccination with Recombinant Subolesin Antigens Provides Cross-Tick Species Protection in Bos indicus and Crossbred Cattle in Uganda
}

\author{
Paul D. Kasaija ${ }^{1,2,+}$, Marinela Contreras ${ }^{1,3,+}{ }^{\oplus}$, Fredrick Kabi ${ }^{2}$, Swidiq Mugerwa ${ }^{2}(\mathbb{C}$ and \\ José de la Fuente $1,4, *$ (D) \\ 1 SaBio, Instituto de Investigación en Recursos Cinegéticos (IREC), Consejo Superior de Investigaciones \\ Científicas (CSIC), Universidad de Castilla-La Mancha (UCLM)-Junta de Comunidades de Castilla-La \\ Mancha (JCCM), Ronda de Toledo s/n, 13005 Ciudad Real, Spain; kpauldavis@gmail.com (P.D.K.); \\ marinelacr@hotmail.com (M.C.) \\ 2 National Livestock Resources Research Institute (NaLIRRI/NARO), P.O. Box 5704 Kampala, Uganda; \\ freddykabi@gmail.com (F.K.); mugerwaswidiq@gmail.com (S.M.) \\ 3 Interdisciplinary Laboratory of Clinical Analysis, Interlab-UMU, Regional Campus of International \\ Excellence Campus Mare Nostrum, University of Murcia, Espinardo, 30100 Murcia, Spain \\ 4 Department of Veterinary Pathobiology, Center for Veterinary Health Sciences, Oklahoma State University, \\ Stillwater, OK 74078, USA \\ * Correspondence: jose_delafuente@yahoo.com or josedejesus.fuente@uclm.es \\ + These authors contributed equally.
}

Received: 10 April 2020; Accepted: 16 June 2020; Published: 18 June 2020

\begin{abstract}
Cattle tick infestations and transmitted pathogens affect animal health, production and welfare with an impact on cattle industry in tropical and subtropical countries. Anti-tick vaccines constitute an effective and sustainable alternative to the traditional methods for the control of tick infestations. Subolesin (SUB)-based vaccines have shown efficacy for the control of multiple tick species, but several factors affect the development of new and more effective vaccines for the control of tick infestations. To address this challenge, herein we used a regional and host/tick species driven approach for vaccine design and implementation. The objective of the study was to develop SUB-based vaccines for the control of the most important tick species (Rhipicephalus appendiculatus, $R$. decoloratus and Amblyomma variegatum) affecting production of common cattle breeds (Bos indicus and B. indicus $\times$ B. taurus crossbred) in Uganda. In this way, we addressed the development of anti-tick vaccines as an intervention to prevent the economic losses caused by ticks and tick-borne diseases in the cattle industry in Uganda. The results showed the possibility of using SUB antigens for the control of multiple tick species in B. indicus and crossbred cattle and suggested the use of $R$. appendiculatus SUB to continue research on vaccine design and formulation for the control of cattle ticks in Uganda. Future directions would include quantum vaccinology approaches based on the characterization of the SUB protective epitopes, modeling of the vaccine E under Ugandan ecological and epidemiological conditions and optimization of vaccine formulation including the possibility of oral administration.
\end{abstract}

Keywords: cattle; tick; vaccine; subolesin; akirin; uganda

\section{Introduction}

Cattle tick ectoparasites affect animal health, production and welfare particularly in tropical and subtropical countries of the world [1-3]. In particular in Uganda where this study was conducted, tick-borne diseases (TBD) such as East Coast fever (caused by Theileria parva), babesiosis (caused by 
Babesia bigemina), anaplasmosis (caused by Anaplasma marginale) and heartwater (caused by Ehrlichia ruminantium) affect cattle production with estimated losses of over USD 1.1 billion annually [4].

Traditional methods for the control of tick infestations and TBD have been based on acaricides, repellents, antibiotics, cattle breeding and extension education about recommended practices to reduce exposure to ticks [5-7]. However, these practices have been only partially successful and drug resistance and contamination impact on public and environmental health constitute important limitations $[6,8]$. Taken together, these facts encourage the development of vaccines as effective and environmentally sound control strategies for the integrated control of tick infestations and TBD [6,7,9-11].

The first and only vaccines against ectoparasites were registered in the early 1990s for the control of cattle tick infestations [9]. These vaccines based on the Rhipicephalus microplus midgut concealed antigen BM86 proved to reduce cattle tick populations and the use of acaricides when applied over time for cattle vaccination $[9,12,13]$. Recently, research has advanced the identification and characterization of tick protective antigens such as subolesin (SUB) $[13,14]$, but several factors affect the development of new and more effective vaccines for the control of tick infestations $[7,15]$.

One of the major limitations for developing effective vaccines for the control of tick infestations and tick-borne pathogens is the lack of funding and the need to fulfil the regulatory requirements for vaccine registration. To address this challenge, we support the use of regional and host/tick species driven approaches for vaccine design and implementation $[4,16]$.

In the study reported here and based on the collaboration between the Spanish Instituto de Investigación en Recursos Cinegéticos (IREC) and the National Agricultural Research Organization of Uganda (NARO) [4], we focused on the development of a SUB-based vaccine for the control of the most important tick species (Rhipicephalus appendiculatus, $R$. decoloratus and Amblyomma variegatum) affecting production of common cattle breeds (Bos indicus and B. indicus $\times$ B. taurus crossbred) in Uganda. SUB, the ortholog of akirin (AKR) in ticks was chosen as a vaccine antigen because it is highly conserved, both genetically and functionally, across all tick species and has shown protection for the control of tick infestations and pathogen infection and transmission [17]. In this way, we addressed the development of anti-tick vaccines as one of the recently proposed measures by the Food and Agriculture Organization of the United Nations (FAO) in conjunction with the Government of Uganda [4] to prevent the economic losses caused by ticks and TBD in the cattle industry in Uganda. The results showed the possibility of using SUB antigens for the control of multiple tick species in $B$. indicus and crossbred cattle and suggested the use of $R$. appendiculatus SUB to continue research on vaccine design and formulation for the control of cattle ticks in Uganda.

\section{Materials and Methods}

\subsection{Ethics Statement}

The experimental cattle were treated in accordance to the Uganda National Council of Science and Technology (UNCT) guiding Principles for Biomedical Research Involving Animals. The experiments were conducted under approval of NARO Institutional Animal Care and Use Committee (IACUC) (No. 2020-0802-20).

\subsection{Cattle}

Bos indicus and B. indicus $\times$ B. taurus crossbred cattle breeds were included in the vaccination trials. Cattle had no previous exposure to ticks. Before the experiment, the general health status of the animals was assessed with particular attention to theileriosis and babesiosis. Blood samples were collected and screened both microscopically and by PCR for the identification of piroplasms and Anaplasma marginale. PCR was conducted with oligonucleotide primers for Babesia and Theileria spp. BAB GF2 (forward: 5'-GTC TTG TAA TTG GAA TGA TGG-3' and reverse: 5'-CCA AAG ACT TTG ATT TCT CTC-3') and Anaplasma spp. 16SANA (forward: 5'-CAGAGTTTGATCCTGGCTCAGAACG-3' and reverse: $5^{\prime}$-GAGTTTGCCGGGACTTCTTCTGTA-3') as previously described $[18,19]$. Healthy $B$. indicus $(n=$ 
20) and crossbred $(n=20)$ calves aged at least ten months were selected for the study. The animals were housed individually in arthropod-free, well ventilated isolation pens and fed on fodder and $20 \%$ protein concentrate receiving water ad libitum.

\subsection{Ticks}

Ticks $R$. appendiculatus, $A$. variegatum and $R$. decoloratus were originally collected from different agroecological zones of Uganda in 2012 and subsequently maintained by feeding under controlled conditions on calves and rabbits in the NaLIRRI tick colony. Ticks were screened by PCR as described for cattle and were negative for tick-borne pathogens Babesia, Theileria and Anaplasma spp. eggs oviposited by various ticks of the same species were pooled and hatched larvae were first kept for 15 days in humidity chambers at $12 \mathrm{~h}$ light:12h dark photoperiod, $20^{\circ} \mathrm{C}$ and $95 \%$ relative humidity before application on to the animals.

\subsection{Cloning of SUB-Coding Genes and Sequence Analysis}

The genes coding for SUB were cloned from adult female $R$. appendiculatus, A. variegatum and $R$. decoloratus tick tissues. Total RNA was extracted from midguts of the three tick species using TRI Reagent (Sigma-Aldrich, St. Louis, MO, USA) following the manufacturer's instructions. The RNA was used for cDNA synthesis using the iScript cDNA synthesis Kit (Bio-Rad Laboratories Inc., Hercules, CA, USA) followed by sub gene amplification by PCR using gene-specific forward $(\mathrm{F})$ and reverse $(\mathrm{R})$ oligonucleotide primers for each tick species ( $R$. appendiculatus, F: 5'-CCAATGGCTTGTGCGACATTAAA-3' , R: 5' -CGACAAATAGCTGGGCGTA-3'; A. variegatum, F: 5'-CACCATGGCTTGCGCAACATTAAA-3', R: 5' -TTTGGTCGTACGTAAACTTG-3' ; $R$. decoloratus, F: 5'-CACCATGGCTTGCGCAACATTAAA-3', R: 5' -TTTGGTCGTACGTAAACTTGAC-3'). SUB sequences were deposited in the GenBank (Accession numbers MT241514, MT241515, MT252964). For SUB amino acid sequence analysis, entries for Rhipicephalus spp. complete sequences ( $n$ = 31) and Amblyomma spp. partial and complete sequences $(n=6)$ available on GenBank (https://www.ncbi.nlm.nih.gov/protein; accessed 20 March 2020) were used together with sequences from Ugandan tick strains for a total of 33 and 7 sequences for Rhipicephalus and Amblyomma spp., respectively. Ixodes scapularis SUB (AAV67031.1) was used as the outgroup. Sequences were aligned using the COBALT constraint-based multiple alignment tool (https://www.ncbi.nlm.nih.gov/tools/ cobalt/cobalt.cgi?LINK_LOC=BlastHomeLink). The evolutionary analysis was performed using the maximum likelihood method and Jones-Taylor-Thornton (JTT) matrix-based model [20]. Trees with the highest log likelihood (-1075.01 and -722.52 for Rhipicephalus and Amblyomma spp., respectively) were used. Initial trees for the heuristic search were obtained automatically by applying neighbor-joining (NJ) and BioNJ algorithms to a matrix of pairwise distances estimated using a JTT model, and then selecting the topology with superior log likelihood value. For Rhipicephalus spp., a discrete Gamma distribution was used to model evolutionary rate differences among sites (five categories; +G, parameter = 1.7321). Evolutionary analyses were conducted using MEGA X [21].

\subsection{Production of Recombinant SUB Antigens and Vaccine Formulation}

For the production of recombinant SUB proteins, Escherichia coli BL21 Star (DE3) One Shot cells (Invitrogen-Life Technologies, Inc., Grand Island, NY, USA) were transformed with the target sub gene cloned into the pET101/D-TOPO expression vector (Ref. K101-01, Invitrogen-Life Technologies). The cells were cultured in $10 \mathrm{~mL}$ Luria-Bertani (LB) medium containing $50 \mu \mathrm{g} / \mathrm{mL}$ ampicillin (Sigma-Aldrich) and 0.5\% glucose (Laboratorios CONDA S.A., Madrid, Spain) overnight at $37^{\circ} \mathrm{C}$ with shaking. Cells from $9 \mathrm{~mL}$ overnight culture were inoculated into $1000 \mathrm{~mL}$ flasks containing $200 \mathrm{~mL} \mathrm{LB}$ with $50 \mu \mathrm{g} / \mathrm{mL}$ ampicillin and $0.5 \%$ glucose and incubated at $37{ }^{\circ} \mathrm{C}$ and shaking at $200 \mathrm{rpm} \mathrm{for} 2 \mathrm{~h}$ followed by $4-6 \mathrm{~h}$ after addition of $0.5 \mathrm{mM}$ final concentration of isopropyl- $\beta$-dthiogalactopyranoside (IPTG, Sigma-Aldrich) for induction of gene expression for SUB production. The cells were harvested by centrifugation at $3900 \times \mathrm{g}$ for $15 \mathrm{~min}$ at $4{ }^{\circ} \mathrm{C}$ and the cell pellet stored at $-80{ }^{\circ} \mathrm{C}$ until purification. 
One gram cells were resuspended in $5 \mathrm{~mL}$ of lysis buffer $\left(50 \mathrm{mM} \mathrm{K}_{3} \mathrm{PO}_{4}, 400 \mathrm{mM} \mathrm{NaCl}, 100 \mathrm{mM}\right.$ $\mathrm{KCl}, 7 \mathrm{M}$ Urea, $10 \mathrm{mM}$ imidazole, pH 7.8) containing a protease inhibitor (Ref. 04693132001, Roche, San Cugat del Vallés, Barcelona, Spain) and disrupted using a cell sonicator (Model MS73; Bandelin Sonopuls, Berlin, Germany). After disruption, the insoluble protein fraction containing the antigens as inclusion bodies were collected in the supernatant by centrifugation at $10,000 \times g$ for 15 min at $4{ }^{\circ} \mathrm{C}$ and stored at $-20^{\circ} \mathrm{C}$. Recombinant proteins were purified by Ni affinity chromatography using $1 \mathrm{~mL}$ HisTrap FF columns mounted on the AKTA ${ }^{\mathrm{TM}}$ fast protein liquid chromatography (AKTA-FPLC) system (GE Healthcare, Piscataway, NJ, USA) in the presence of 7M urea. The eluted fraction containing the purified proteins was dialyzed overnight against 1000 volumes of PBS (137 mM NaCl, $2.7 \mathrm{mM} \mathrm{KCl}$, $10 \mathrm{mM} \mathrm{Na}_{2} \mathrm{HPO}_{4}, 1.8 \mathrm{mM} \mathrm{KH} \mathrm{PO}_{4}$ ) pH 7.4 for $12 \mathrm{~h}$ at $4{ }^{\circ} \mathrm{C}$. Protein concentration was determined using bicinchoninic acid (Ref. 23225, Pierce BCA Protein Assay Kit, Thermo Scientific, Rockford, IL, USA).

Recombinant proteins were adjuvated in Montanide ISA 50 V2 (Seppic, Paris, France) in a stable water in oil (W/O) vaccine emulsion at a concentration of $50 \mu \mathrm{g}$ SUB per $\mathrm{ml}$ and stored at $4{ }^{\circ} \mathrm{C}$ [22].

\subsection{Western Blot Analysis of Recombinant SUB Antigens}

Ten $\mu$ g per well of purified recombinant proteins were loaded onto an SDS-12\% polyacrylamide gel (Life Science, Hercules, CA, USA). Gels were either stained with Coomassie Brilliant Blue or used for Western blot analysis. For Western blot analysis, the gel was transferred to a nitrocellulose membrane which was then blocked with 5\% BSA (Sigma-Aldrich) for $2 \mathrm{~h}$ at RT, washed four times with Tris-buffered saline (TBS; $50 \mathrm{mM}$ Tris-Cl, pH 7.5, $150 \mathrm{mM} \mathrm{NaCl}, 0.5 \%$ Tween 20) and incubated with pooled sera collected from vaccinated cattle at day 60 . Sera with primary antibodies were used at a 1:300 dilution in TBS, and the membrane was incubated overnight at $4{ }^{\circ} \mathrm{C}$ and washed four times with TBS. The membrane was then incubated with an anti-bovine IgG-horseradish peroxidase (HRP) conjugate (Sigma-Aldrich) diluted 1:5000 in TBS with 3\% BSA (BSA/TBS). The membrane was washed five times with TBS and finally developed with 3,3', 5,5'-tetramethylbenzidine (TMB) stabilized substrate for HRP (Promega, Madrid, Spain) according to the manufacturer recommendations. Molecular weight markers (Spectra multicolor broad range protein ladder; Thermo Scientific) were used.

\subsection{Vaccination Trials}

The vaccination trials were conducted using a double blinded design, i.e., each of the vaccine formulations was coded as S1, S2, S3, S4 and S5 such that neither researchers involved in vaccination and data collection or in data analysis knew which vial contains what vaccine formulation until the completion of the trial. Calves of each breed were randomly assigned to five groups of four animals each. Calves in each group were vaccinated with vaccine formulations containing each of the SUB antigens, a cocktail of all three SUB antigens or adjuvant alone as control. The animals were injected intramuscularly in the neck muscles with $2 \mathrm{~mL}$ vaccine (100 $\mu \mathrm{g}$ SUB per dose) on days 0, 30 and 60. Fifteen days after the last immunization (day 75), crossbred cattle were challenged with $R$. appendiculatus, $R$. decoloratus and $A$. variegatum tick larvae, simultaneously. The three tick infestation treatments were done on each animal using two ear-bags for $R$. appendiculatus and $A$. variegatum and a cell glued on the back of the animal for $R$. decoloratus. B. indicus cattle were infested with $R$. appendiculatus and A. variegatum tick larvae simultaneously as described for crossbred calves. Infestation with $R$. decoloratus was not included in $B$. indicus due to the limited number of available larvae and the highest resistance to one-host tick species in this cattle breed [23]. All data was collected and analyzed from each individual calve.

For the three host tick species, $R$. appendiculatus and A. variegatum, approximately 300 larvae were applied on each animal. The larvae were allowed to attach and engorge for two weeks. The ear bags were then removed, and successfully engorged ticks counted, weighed and incubated for molting at $20^{\circ} \mathrm{C}$ and $95 \%$ relative humidity. A 15-day-old batch of 200 nymphs were applied on to each ear for two weeks and engorged nymphs were collected, counted, weighed and incubated for molting 
to adults. Finally, 30 starved adult male and female ticks were applied on to the calf's ear at a one male per three female ratio in the ear-bags. After two weeks, the ear-bags were removed and engorged female ticks collected, counted, weighed individually and incubated for oviposition. Eggs laid per tick were weighed for each calf and incubated for hatching. Larvae obtained from each egg batch were weighed.

For the one host tick, $R$. decoloratus, approximately 300 larvae were applied on to each calf using a cell glued to the back of the animal. The cells were left in position for 28-30 days to allow all the developmental stages to take place on the host. The cells were then removed, and adult engorged ticks collected, counted, weighed individually and incubated for oviposition. The eggs mass per female tick was weighed and incubated for hatching. The recovered larvae per egg batch were weighed.

\subsection{Data Collection and Analysis of Vaccine Efficacy}

The effect of the vaccination on tick life cycle was determined using the formulae previously described $[13,24,25]$.

Effect on the number of engorged larvae (DL), nymphs (DN) and adult female ticks (DA):

$$
\text { DL, DN, DA }(\%)=100(1-\mathrm{NTV} / \mathrm{NTC})
$$

where DL, DN, DA (\%) is the percentage reduction of ticks, NTV is the number of ticks dropping off the animals in the vaccinated group and NTC is the number of ticks dropping off the animals in the control group.

Effect on the molting of tick larvae (DMn) and nymphs (DMa):

$$
\text { DMn, DMa }(\%)=100(1-\text { MTV/MTC })
$$

where DMn, DMa (\%) is the percentage reduction of average molting of ticks, MTV is the average molting of ticks in the vaccinated group and MTC is the average molting of ticks in the control group

Effect on the tick oviposition (DO):

$$
\mathrm{DO}(\%)=100(1-\mathrm{PATV} / \mathrm{PATC})
$$

where DO $(\%)$ is the percentage reduction in tick oviposition, PATV is the average weight of the eggs per survived tick in the vaccinated group and PATC is the average weight of the eggs per survived tick in the control group.

Effect on fertility (DF):

$$
\mathrm{DF}(\%)=100(1-\mathrm{PPLOV} / \mathrm{PPLOC})
$$

where DF (\%) is the percentage reduction in egg fertility, PPLOV is the average weight of the larvae per gram of eggs in the vaccinated group and PPLOC is the average weight of the larvae per gram of eggs in the control group.

Vaccine efficacy (E):

$$
\mathrm{E}(\%)=100(1-(\mathrm{DL} \times \mathrm{DMn} \times \mathrm{DN} \times \mathrm{DMa} \times \mathrm{DA} \times \mathrm{DO} \times \mathrm{DF})) .
$$

Results were included in Supplementary Materials Data S1. Data were analyzed statistically to compare results for each tick species between individuals fed on vaccinated and adjuvant/saline injected control cattle by Chi-square test ( $p=0.05 ; n=4$ biological replicates). Only parameters with statistically significant differences were included in the vaccine $\mathrm{E}$ calculation. Total vaccine $\mathrm{E}$ for each antigen in all tick species was compared between $B$. indicus and crossbred cattle by a Student's t-test with unequal variance ( $p=0.05 ; n=2-3$, i.e., three tick species in crossbred cattle or two tick species in B. indicus). A Spearman's Rho correlation analysis (https://www.socscistatistics.com/tests/spearman/Default2.aspx) 
was performed between total vaccine E values for each antigen in all cattle breeds and tick species ( $p=0.05 ; n=5$, i.e., three tick species in crossbred cattle plus two tick species in B. indicus).

\subsection{Characterization of the Antibody Response in Vaccinated Calves}

Blood samples were collected before each vaccination (days 0, 30 and 60), at day 45 between second and third vaccinations and at the end of the experiment (days 180 or 195 for B. indicus and crossbred cattle, respectively). The obtained serum was stored at $-20^{\circ} \mathrm{C}$ until analysis. Serum IgG antibody titers were determined using an indirect antigen-specific ELISA $[25,26]$. Purified recombinant SUB antigens $(0.1 \mu \mathrm{g}$ in $50 \mu \mathrm{L}$ of carbonate-bicarbonate buffer; Sigma-Aldrich) per well were used for overnight coating of high absorption capacity polystyrene microtiter ELISA plates at $4{ }^{\circ} \mathrm{C}$. Plates were blocked with $200 \mu \mathrm{L} /$ well of blocking solution (10\% fetal bovine serum in PBS, $137 \mathrm{mM} \mathrm{NaCl}, 2.7 \mathrm{mM} \mathrm{KCl}, 10 \mathrm{mM} \mathrm{Na} 2 \mathrm{HPO}$, $1.8 \mathrm{mM}$ KH2PO4 and pH 7.4) (Sigma-Aldrich). The sera were serially diluted to 1:10, 1:100, 1:1000 and 1:10,000 v/v in blocking solution (optimal dilution, 1:1000). Plates were then incubated with $50 \mu \mathrm{L} /$ well of diluted sera overnight at $4{ }^{\circ} \mathrm{C}$, followed by three washes using PBS and $0.1 \%$ Tween 20 (PBST) and an incubation with PBS-diluted (1:10,000) rabbit anti-bovine IgG-HRP conjugates (Sigma-Aldrich) for $1 \mathrm{~h}$ at room temperature (RT). After three washes with PBST, the chromogenic reaction was developed with 3,3'5,5'-tetramethylbenzidine (Sigma-Aldrich), stopped with $50 \mu \mathrm{L} /$ well of $3 \mathrm{~N} \mathrm{H}_{2} \mathrm{SO}_{4}$ and the optical density at $450 \mathrm{~nm}$ (O.D.450 nm) was determined in an ELISA plate reader. Antibody titers were expressed as the O.D.450 nm values and compared between vaccinated and control groups using a one-way ANOVA test (https://www.socscistatistics.com/tests/anova/default2.aspx) ( $p=0.05 ; n=4$ biological replicates). In addition, a correlation analysis was performed in Microsoft Excel between the values of the parameters of Rhipicephalus spp. tick life stages used for vaccine E calculation that showed significant differences with at least three of the SUB vaccine formulations and the anti-SUB antibody titers against $R$. appendiculatus SUB at day 60 before tick challenge in individual animals. Data was analyzed using a Spearman's Rho correlation analysis (https://www.socscistatistics.com/tests/spearman/Default2.aspx) ( $p=0.05 ; n=20$, i.e., 4 animals for each of the 5 vaccine formulations including the control).

\section{Results and Discussion}

\subsection{Experimental Design and Rationale}

The study was designed to approach the objective of evaluating the protective capacity of recombinant SUB-based vaccines against multiple tick species infesting cattle in Uganda (Figure 1). The experimental design included the cloning and analysis of SUB-coding genes in Ugandan strains of $R$. appendiculatus, $R$. decoloratus and A. variegatum, and production of recombinant proteins and vaccine formulations with single and all combined antigens. SUB, the ortholog of AKR in ticks was chosen as a vaccine antigen because it is highly conserved both genetically and functionally across all tick species and has shown protection in cattle for the control of tick infestations and pathogen infection and transmission $[17,27,28]$. Vaccination trials were conducted in the most common cattle breeds (Bos indicus and B. indicus $\times B$. taurus crossbred) in Uganda using four calves per group which were infested with $R$. appendiculatus and A. variegatum larvae, nymphs and adults. Due to the limited number of available larvae and the high resistance of $B$. indicus cattle to one-host tick species [23], only crossbred cattle were infested with $R$. decoloratus larvae. The effect of vaccination on cattle antibody response and on different tick developmental stages (DL, DMn, DN, DMa, DA, DO and DF) was used to evaluate vaccine E. Only parameters with statistically significant differences were included in the vaccine E calculation. 


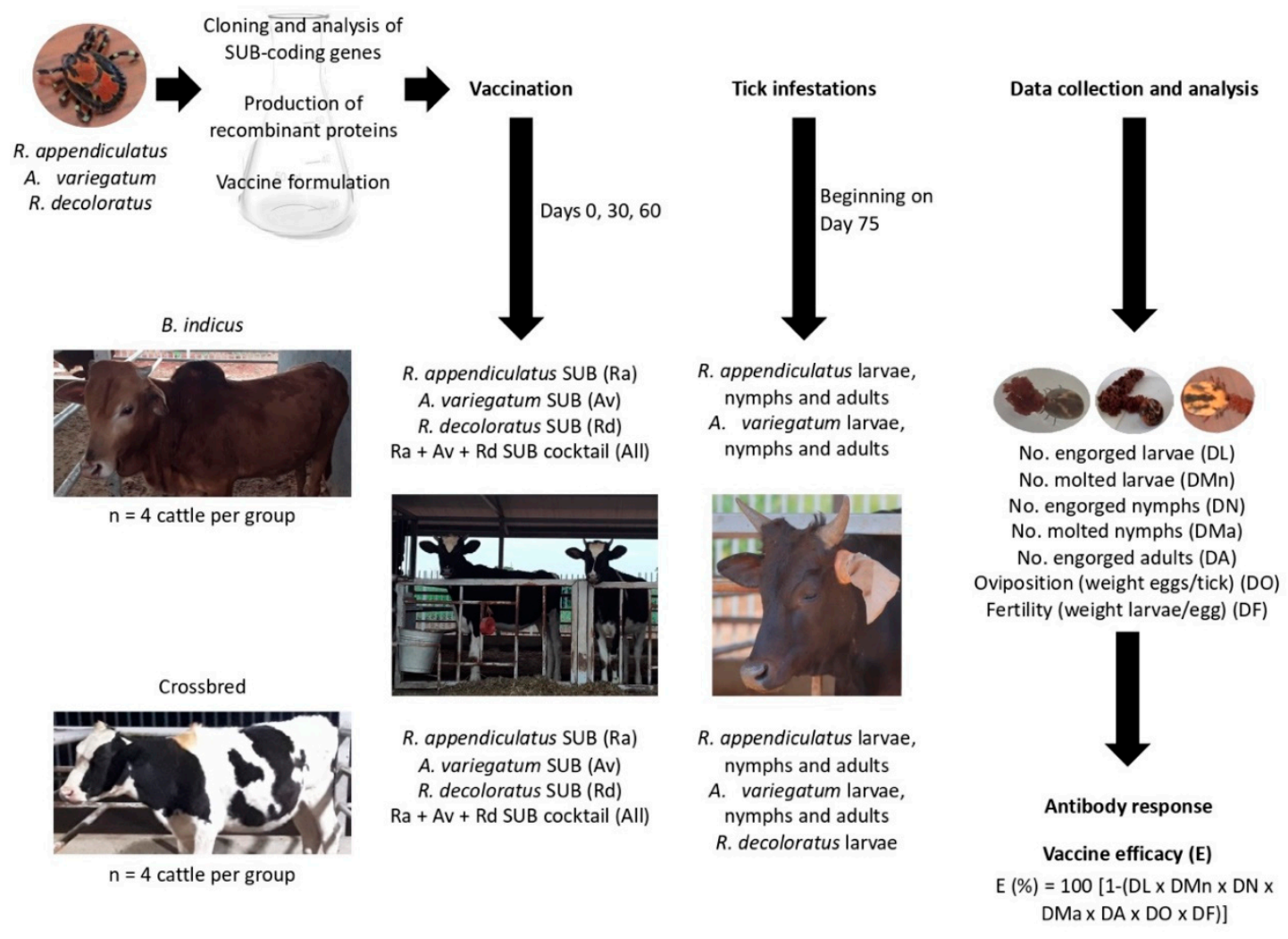

Figure 1. Experimental design. The study design included the cloning and analysis of subolesin (SUB)-coding genes in Ugandan strains of $R$. appendiculatus, $R$. decoloratus and A. variegatum, followed by production of recombinant proteins and vaccine formulations with single and all combined antigens. Vaccination trials were conducted in the most common cattle breeds (Bos indicus and B. indicus $\times B$. taurus crossbred) in Uganda using 4 calves/group and infested with $R$. appendiculatus and $A$. variegatum larvae, nymphs and adults and $R$. decoloratus larvae in crossbred cattle only. The effect of vaccination on cattle antibody response and on different tick developmental stages (number of engorged larvae (DL), nymphs (DN) and adult female ticks (DA), molting of tick larvae (DMn) and nymphs (DMa), oviposition (DO) and fertility (DF) was used to evaluate vaccine $\mathrm{E}$.

\subsection{SUB Protein Sequences Are Highly Conserved but Show Distinctive Amino Acid Residues}

The SUB-coding genes were cloned from R. appendiculatus, R. decoloratus and A. variegatum Ugandan tick strains. In accordance with previous results [29-31], protein sequence analysis showed high sequence homology (Figure 2A,B). The Ugandan $R$. appendiculatus sequence clustered together with $R$. microplus from Asia while Ugandan $R$. decoloratus was closely related to a $R$. appendiculatus from USA (Figure 2A). With a limited number of sequences available, Ugandan $A$. variegatum clustered together with $A$. variegatum and $A$. hebraeum from America (Figure $2 \mathrm{~B}$ ). However, when focusing on Ugandan tick species, SUB protein sequences showed a high homology (75\% amino acid identity) but with some distinctive amino acid residues (Figure 3A). Recombinant proteins were produced in E. coli with the expected molecular weight (29 and $30 \mathrm{kDa}$ for Rhipicephalus spp. and A. variegatum, respectively) for both monomer and dimer forms, which are commonly found in SUB/AKR with functional implications [32] (Figure 3B). 
A AFH57341.1 India (Rhipicephalus microplus) AFH57344.1 India (Rhipicephalus microplus) AIS66740.1 China(Rhipicephalus microplus) AFH57340.1 India (Rhipicephalus microplus) AFL65875.1 India (Rhipicephalus microplus) AFL65879.1 India (Rhipicephalus microplus) AFH57334. 1 India (Rhipicephalus microplus) AFH57346. 1 India (Rhipicephalus microplus) AFH57338.1 India (Rhipicephalus microplus)

63- AFQ91884.1 India (Rhipicephalus microplus) - MT241515 Uganda (Rhipicephalus appendiculatus)

ABZ89745.1 China (Rhipicephalus microplus)

AFQ91883.1 India (Rhipicephalus microplus)

AFH57343.1 India (Rhipicephalus microplus)

AFH57336. 1 India (Rhipicephalus microplus)

AFQ91885.1 India (Rhipicephalus microplus)

AFH57339. 1 India (Rhipicephalus microplus)

AFH57342. 1 India (Rhipicephalus microplus)

AFH57337.1 India (Rhipicephalus microplus)

- AFL65878.1 India (Rhipicephalus microplus)

AFH57345.1 India (Rhipicephalus microplus)

AFL65877. 1 India (Rhipicephalus microplus)

AFL65876.1 India (Rhipicephalus microplus)

AFH57347.1 India (Rhipicephalus microplus)

AGI44622.1 South Africa (Rhipicephalus evertsi)

5 ABA62331.1 USA (Rhipicephalus appendiculatus)

MT241514 Uganda (Rhipicephalus decoloratus)

${ }_{87}$ AlS66739.1 China (Rhipicephalus haemaphysaloides)

AKM12409.1 China (Rhipicephalus haemaphysaloides)

50 AGI44621.1 Brazil(Rhipicephalus sanguineus)

79 ABA62332.1 USA (Rhipicephalus sanguineus)

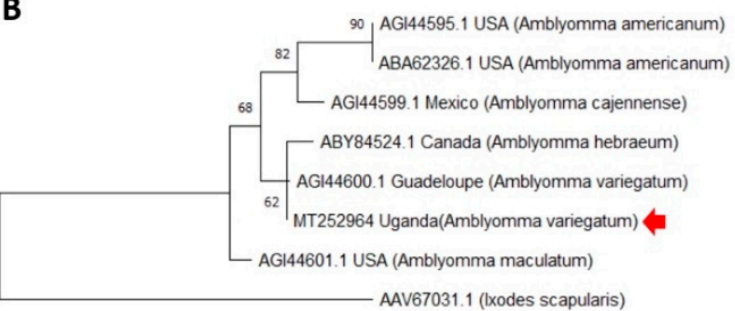

0.020

AAV67031.1 (Ixodes scapularis)

JAP81090.1 South Africa (Rhipicephalus appendiculatus)

Figure 2. Phylogenetic analysis of SUB protein sequences. The evolutionary analysis was performed using the maximum likelihood method and JTT matrix-based model in Mega X. (A) Rhipicephalus spp.: The tree with the highest log likelihood $(-1075.01)$ is shown. The percentage of trees in which the associated taxa clustered together is shown next to the branches. A discrete Gamma distribution was used to model evolutionary rate differences among sites ( 5 categories; $+\mathrm{G}$, parameter $=1.7321$ ). The tree is drawn to scale, with branch lengths measured in the number of substitutions per site. This analysis involved 34 amino acid sequences with a total of 192 positions in the final dataset. (B) Amblyomma spp.: The tree with the highest log likelihood (-722.52) is shown. The percentage of trees in which the associated taxa clustered together is shown next to the branches. The tree is drawn to scale, with branch lengths measured in the number of substitutions per site. This analysis involved 8 amino acid sequences with a total of 184 positions in the final dataset. Sequences from Ugandan tick strains are marked with a red arrow. 
A

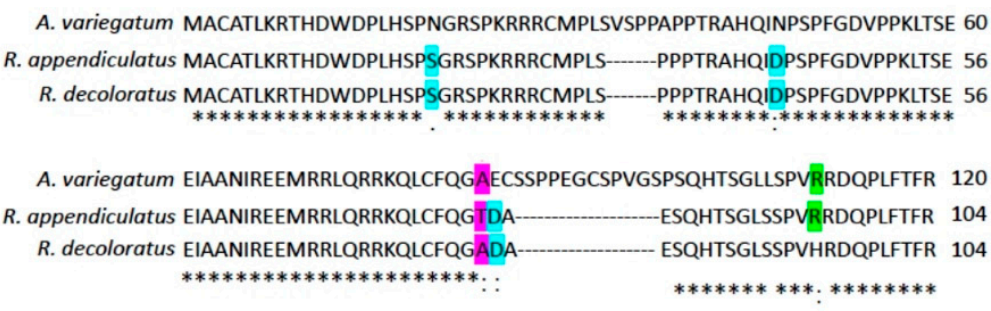

A. variegatum QVGLICERMMKERESQIREEYDHVLSTKLAEQYDTFVKFTYDQIQKRFEGATPSYLSKGELNSKLE 186 R. appendiculatus QVGLICERMMKERESKIREEYDHVLSTKLAEQYDTFVKFTYDQIQKRFEGATPSYLS - 161 R. decoloratus QVGLICERMMKERESKIREEYDHVLSTKLAEQYDTFVKFTYDQ- 147

B $* * * * * * * * * * * * * * * * * * * * * * * * * * * * * * * * * * * * * * * *$

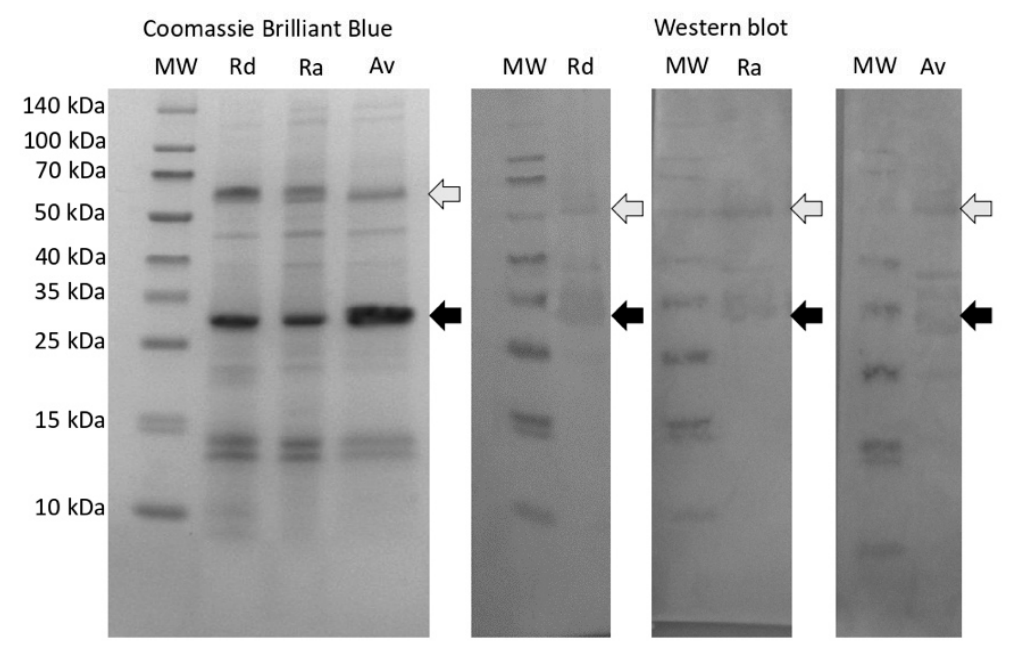

Figure 3. Production of recombinant R. appendiculatus, R. decoloratus and A. variegatum SUB in E. coli. (A) alignment of SUB amino acid protein sequences. Distinctive amino acid residues are highlighted (blue: Identical only between $R$. appendiculatus and $R$. decolortus, green: Identical only between $A$. variegatum and $R$. appendiculatus and pink: Identical only between $A$. variegatum and $R$. decoloratus). Conserved residues between all sequences are indicated with asterisks $\left(^{*}\right)$. (B) ten $\mu$ g per well of purified recombinant proteins were loaded into an SDS-12\% polyacrylamide gel. Gels were stained with Coomassie Brilliant Blue or used for Western blot analysis. For Western blot analysis, the gel was transferred to a nitrocellulose membrane and the membrane was incubated with pooled sera collected from vaccinated cattle at day 60 . The positions of the monomer and dimer recombinant proteins is indicated with black and grey arrows, respectively. Abbreviation: MW, molecular weight markers (Spectra multicolor broad range protein ladder; Thermo Scientific).

\subsection{The Antibody Response Was Higher in All Vaccinated Cattle when Compared to Adjuvant-Alone Treated Controls}

Antibody response to vaccination with SUB has been shown to be the main protective mechanism against tick infestations [33], although cell-mediated immunity may play a role with certain vaccine formulations [34]. Anti-SUB antigen-specific IgG antibody titers were determined on each vaccinated and adjuvant-alone treated controls in sera collected before each vaccination (days 0,30 and 60), at day 45 between second and third vaccinations and at the end of the experiment (days 180 or 195 for B. indicus and crossbred cattle, respectively) (Figure 4A,B). The results showed that antibody titers increased after the first and second vaccination doses but in some cases decreased after the third vaccination dose (Figure $4 \mathrm{~A}, \mathrm{~B})$. These results may reflect antigen-specific and dose effects that have been previously shown in SUB-based vaccines [35,36]. These effects may affect vaccine efficacy and require optimization [37-39]. Nevertheless, the anti-SUB antibody titers were significantly ${ }^{*} p<0.05$ and $\left.{ }^{*} p<0.005\right)$ higher throughout the experiment in vaccinated cattle when compared to controls (Figure 4A,B). 

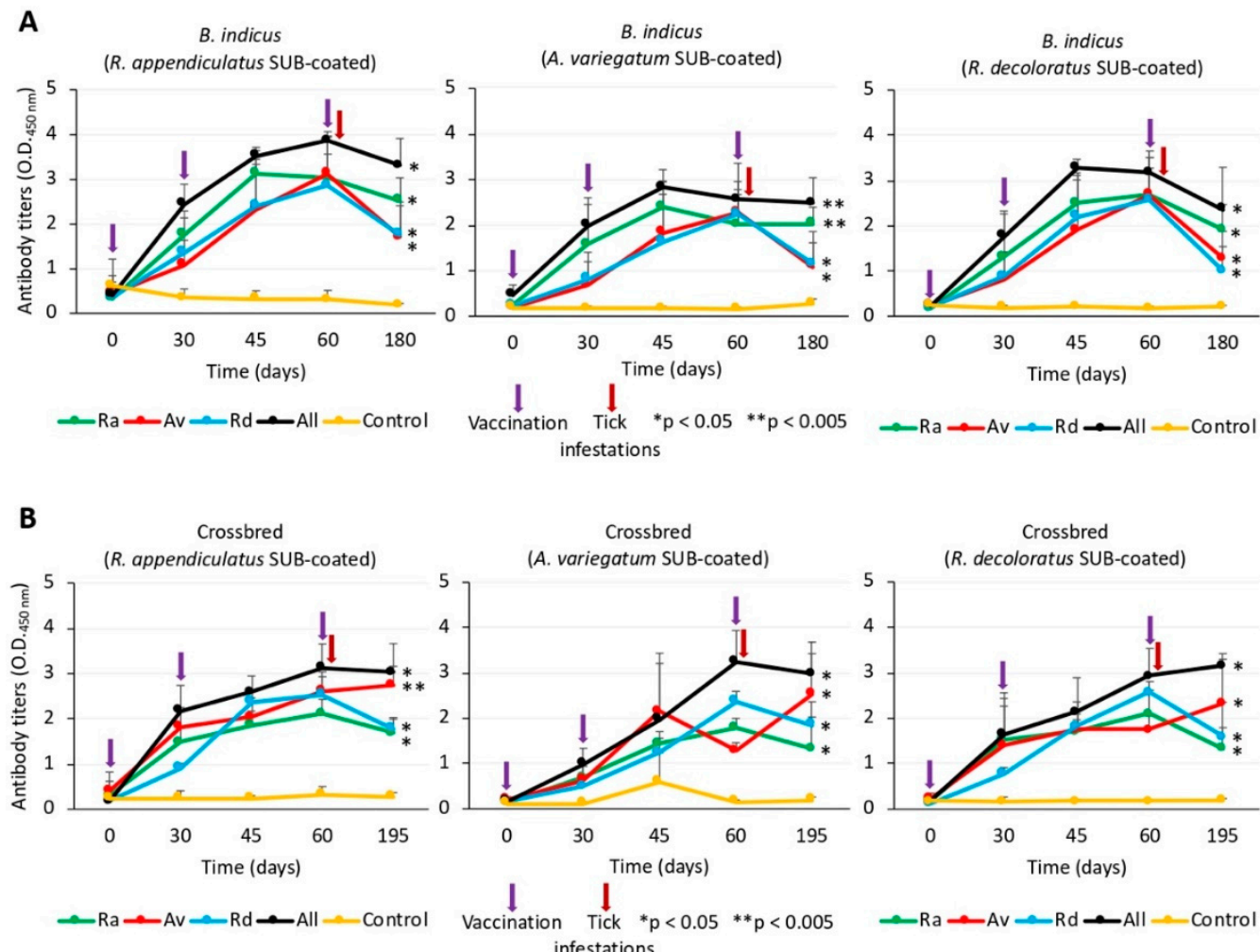

Figure 4. Antibody response in SUB-vaccinated and control cattle. (A) B. indicus cattle. (B) crossbred cattle. Blood samples were collected before each vaccination (days 0,30 and 60; violet arrows), at day 45 between second and third vaccinations and at the end of the experiment (days 180 or 195 for $B$. indicus and crossbred cattle, respectively). Serum IgG antibody titers were determined using an indirect antigen-specific ELISA. Antibody titers were expressed as the $\mathrm{OD}_{450 \mathrm{~nm}}$ values and compared between vaccinated and control groups using a one-way ANOVA test (https://www.socscistatistics.com/tests/ anova/default2.aspx) $\left({ }^{*} p<0.05,{ }^{* *} p<0.005 ; n=4\right.$ biological replicates $)$.

3.4. Vaccination Affected Multiple Tick Developmental Stages with Differences between SUB Antigens, Tick Species and Cattle Breeds

The results of the vaccination showed differences between SUB antigens, tick species and cattle breeds (Data S1, Figure S1A-E, summarized in Figure 5A-E and Table 1). The total number of tick developmental stages included in the analysis corresponded to seven (DL, DMn, DN, DMa, DA, DO, DF) for three-host ticks and three (DA, DO, DF) for the one-host tick, $R$. decoloratus (Figure 5A). Only parameters with statistically significant differences $(p<0.05)$ were included in the analysis. At the SUB antigen level and considering the total number of tick developmental stages that could be affected in all groups $(n=31$; Figure 5B-E), the number of tick developmental stages affected by vaccination varied from 18/31 (58\%) for $R$. appendiculatus SUB to 16/31 (52\%) for A. variegatum SUB, 15/31 (48\%) for R. decoloratus SUB and 13/31 (42\%) for all combined SUB antigens. At the tick species level and considering the total number of developmental stages affected after vaccination in all groups $(n=56$ for $R$. appendiculatus or A. variegatum and $n=12$ for R. decoloratus; Figure 5B-E), the results were similar for $R$. appendiculatus $(28 / 56,50 \%)$, A. variegatum (28/56, 50\%) and $R$. decoloratus $(5 / 12,42 \%)$. When comparing the results between the cattle breeds in all groups, the total number of tick developmental stages that could be affected in $B$. indicus were 56 for the two three-host tick species and in crossbred cattle were 68 for all three tick species (Figure 5B-E). In this case, the results showed 23/56 (41\%) and $39 / 68$ (57\%) affected tick developmental stages in B. indicus and crossbred cattle, respectively. 
Table 1. Results of the SUB vaccination trials.

\begin{tabular}{|c|c|c|c|c|c|c|c|c|}
\hline \multicolumn{9}{|c|}{ Vaccination with $R$. appendiculatus SUB } \\
\hline Group & DL & DMn & DN & DMa & DA & DO & DF & $\mathrm{E}$ \\
\hline \multicolumn{9}{|l|}{ B. indicus } \\
\hline R. appendiculatus & $17 \%$ * & $22 \%$ * & $13 \%$ * & $0 \%$ & $19 \%$ & $6 \% *$ & $0 \%$ & $47 \%$ \\
\hline A. variegatum & $0 \%$ & $25 \%$ * & $0 \%$ & $3 \% *$ & $19 \%$ & $31 \%$ * & $0 \%$ & $50 \%$ \\
\hline \multicolumn{9}{|l|}{ Crossbred } \\
\hline R. appendiculatus & $41 \%$ * & $64 \%$ * & $0 \%$ & $0 \%$ & $51 \% *$ & $0 \%$ & $0 \%$ & $90 \%$ \\
\hline A. variegatum & $34 \%$ * & $44 \%$ * & $19 \%$ * & $25 \%$ * & $0 \%$ & $4 \% *$ & $49 \%$ * & $89 \%$ \\
\hline R. decoloratus & & & & & $0 \%$ & $8 \% *$ & $47 \%$ * & $51 \%$ \\
\hline \multicolumn{9}{|c|}{ Vaccination with $A$. variegatum SUB } \\
\hline Group & DL & DMn & DN & DMa & DA & DO & DF & $E$ \\
\hline \multicolumn{9}{|l|}{ B. indicus } \\
\hline R. appendiculatus & $61 \% *$ & $51 \%$ * & $0 \%$ & $0 \%$ & $29 \%$ * & $0 \%$ & $0 \%$ & $86 \%$ \\
\hline A. variegatum & $0 \%$ & $1 \%$ * & $7 \%$ * & $3 \% *$ & $41 \% *$ & $0 \%$ & $0 \%$ & $47 \%$ \\
\hline \multicolumn{9}{|l|}{ Crossbred } \\
\hline R. appendiculatus & $53 \% *$ & $39 \%$ * & $0 \%$ & $39 \%$ * & $0 \%$ & $4 \% *$ & $0 \%$ & $83 \%$ \\
\hline A. variegatum & $54 \% *$ & $28 \%$ * & $16 \% *$ & $0 \%$ & $0 \%$ & $14 \%$ * & $0 \%$ & $76 \%$ \\
\hline R. decoloratus & & & & & $0 \%$ & $0 \%$ & $72 \%$ * & $72 \%$ \\
\hline \multicolumn{9}{|c|}{ Vaccination with $R$. decoloratus SUB } \\
\hline Group & DL & DMn & DN & DMa & DA & DO & DF & $\mathrm{E}$ \\
\hline \multicolumn{9}{|l|}{ B. indicus } \\
\hline R. appendiculatus & $0 \%$ & $0 \%$ & $25 \% *$ & $0 \%$ & $55 \% *$ & $0 \%$ & $0 \%$ & $66 \%$ \\
\hline A. variegatum & $0 \%$ & $0 \%$ & $32 \% *$ & $0 \%$ & $38 \% *$ & $0 \%$ & $0 \%$ & $58 \%$ \\
\hline
\end{tabular}

\begin{tabular}{|c|c|c|c|c|c|c|c|c|}
\hline \multicolumn{9}{|l|}{ Crossbred } \\
\hline R. appendiculatus & $62 \% *$ & $47 \%$ * & $25 \%$ * & $19 \%$ * & $0 \%$ & $10 \%$ * & $0 \%$ & $89 \%$ \\
\hline A. variegatum & $69 \% *$ & $50 \%$ * & $19 \%$ * & $18 \%$ * & $0 \%$ & $0 \%$ & $39 \%$ * & $94 \%$ \\
\hline R. decoloratus & & & & & $0 \%$ & $0 \%$ & $69 \% *$ & $69 \%$ \\
\hline
\end{tabular}

\begin{tabular}{lcccccccc}
\hline \multicolumn{7}{c}{ Vaccination with the combination of SUB antigens } \\
\hline \multicolumn{1}{c}{ Group } & DL & DMn & DN & DMa & DA & DO & DF & E \\
\hline B. indicus & & & & & & & & \\
\hline R. appendiculatus & $38 \%$ * & $53 \% *$ & $0 \%$ & $0 \%$ & $57 \% *$ & $0 \%$ & $38 \% *$ & $92 \%$ \\
\hline A. variegatum & $0 \%$ & $0 \%$ & $0 \%$ & $0 \%$ & $51 \% *$ & $0 \%$ & $0 \%$ & $51 \%$ \\
\hline Crossbred & & & & & & & & \\
\hline R. appendiculatus & $29 \% *$ & $53 \% *$ & $0 \%$ & $22 \% *$ & $0 \%$ & $0 \%$ & $0 \%$ & $74 \%$ \\
\hline A. variegatum & $27 \% *$ & $0 \%$ & $7 \% *$ & $28 \% *$ & $0 \%$ & $13 \% *$ & $0 \%$ & $69 \%$ \\
\hline$R$. decoloratus & & & & & $0 \%$ & $0 \%$ & $71 \% *$ & $71 \%$ \\
\hline
\end{tabular}

Vaccine $\mathrm{E}(\%)$ was calculated as $100(1-(\mathrm{DL} \times \mathrm{DMn} \times \mathrm{DN} \times \mathrm{DMa} \times \mathrm{DA} \times \mathrm{DO} \times \mathrm{DF}))$, and only parameters with statistically significant differences (Chi-square test; ${ }^{*} p<0.05, n=4$ biological replicates; Data S1) were included in the analysis. 


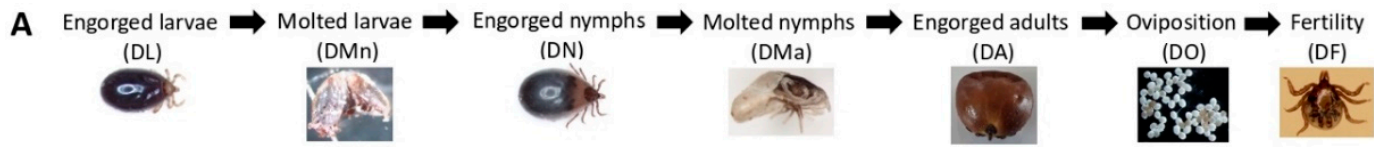

B

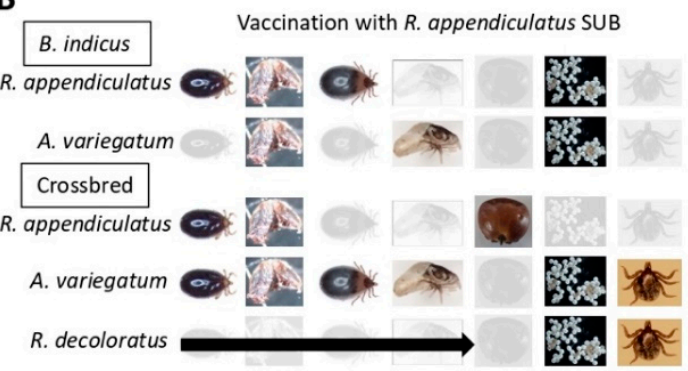

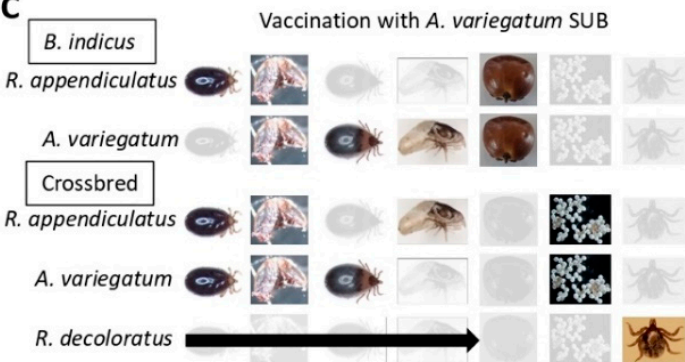

D

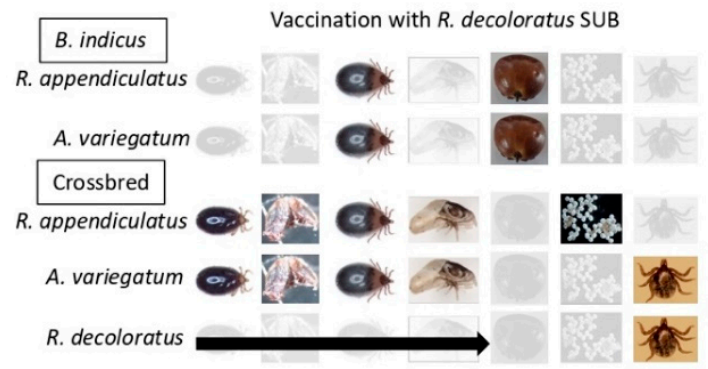

E

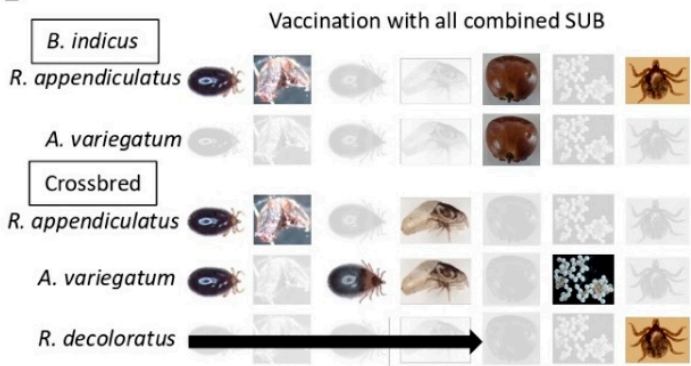

Figure 5. Effect of vaccination with SUB on different tick developmental stages. (A) tick developmental stages included in the analysis. (B) vaccination with $R$. appendiculatus SUB. (C) vaccination with A. variegatum SUB. (D) vaccination with $R$. decoloratus SUB. (E) vaccination with all combined SUB formulation. The tick developmental stages included DL, DN, DA, DMn, DMa, DO and DF. Only parameters with statistically significant differences (Chi-square test; $p<0.05, n=4$ biological replicates; Data S1) are shown here and were included in the vaccine E calculation.

One consideration that may be relevant for evaluating the effect of vaccination on the control of three-host tick infestations is the effect on reducing early tick developmental stages (i.e., DL and DMn, $n=8$ for each SUB vaccine antigen; Figure $5 \mathrm{~B}-\mathrm{E}$ ). Focusing on these parameters, the results showed that $7 / 8(88 \%), 7 / 8(88 \%), 4 / 8(50 \%)$ and $5 / 8(63 \%)$ of the early tick developmental stages were reduced by vaccination with $R$. appendiculatus SUB, A. variegatum SUB, $R$. decoloratus SUB and all combined SUB antigens, respectively.

In summary, these results showed that vaccination with SUB affected tick developmental stages with minor differences between tick species and a higher overall effect of vaccination in crossbred cattle considering all antigen formulations. As found in this study, minor differences between tick species in the efficacy of vaccination with SUB has been reported before [33]. Furthermore, vaccination with $R$. appendiculatus SUB affected the highest number of developmental stages in all tick species with a high reduction of early developmental stages in three-host ticks.

\subsection{The Results of Vaccine E Support the Possibility of Using SUB Antigens for the Control of Multiple Tick Species in Different Cattle Breeds}

The results of the effect of vaccination on the different tick developmental stages translates into vaccine $\mathrm{E}$ (Figure 6A,B). However, in this case the number of affected tick developmental stages is not as relevant as the percentage by which these developmental stages were reduced (Table 1 ). The vaccine E varied from $47 \%$ to $94 \%$ between groups, but in most cases, it was higher than $50 \%$ (Figure $6 \mathrm{~A}, \mathrm{~B}$ ), which was the limit originally set for BM86-based anti-tick vaccines [40]. Except for vaccine E with R. appendiculatus SUB against infestations by R. appendiculatus in crossbred cattle (Figure 6B), vaccine 
E was not the highest when the SUB antigen was of the same origin as the infestation tick species (Figure 6A,B). Furthermore, except for $R$. appendiculatus infestations of $B$. indicus cattle, vaccine $\mathrm{E}$ was not higher with all combined SUB antigens when compared to individual antigens (Figure 6A,B). It has been previously shown that differences in protein metabolism between tick species and immunologic interference with antigen combinations may affect tick vaccine efficacy [41,42]. These facts may at least partially explain why vaccine $\mathrm{E}$ for homologous pairs infesting tick-SUB antigen was generally lower than heterologous pairs or why vaccine $E$ for combined SUB antigen formulations was lower than for individual antigens. As shown above with tick developmental stages, vaccine $E$ tended to be higher in crossbred than in B. indicus cattle with significant differences $(p=0.04)$ for $R$. decoloratus SUB only (Figure 6C). Integrating the results from all tick species and cattle breeds, the total vaccine $\mathrm{E}$ varied from $65 \%$ to $75 \%$ but without significant differences $(p=0.82)$ between SUB antigens (Figure 6D).

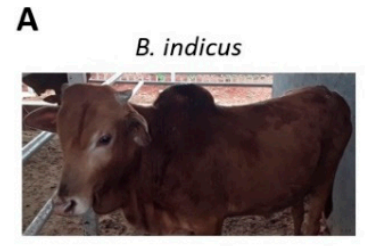

B

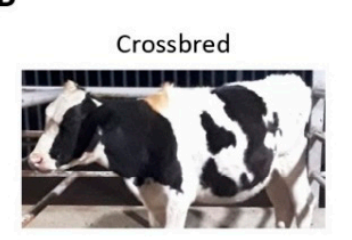

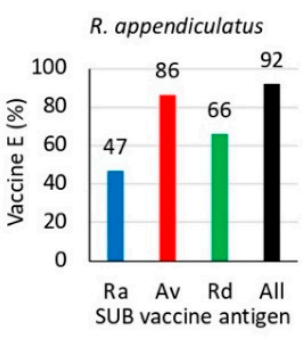

R. appendiculatus

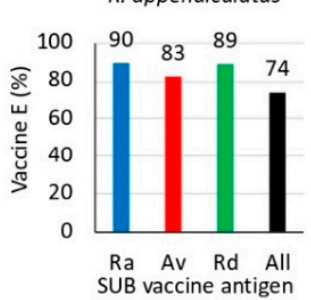

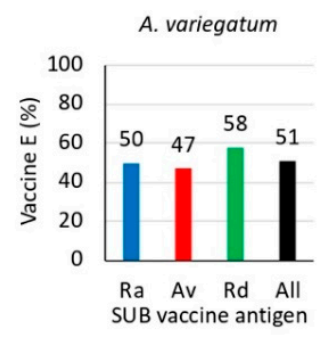

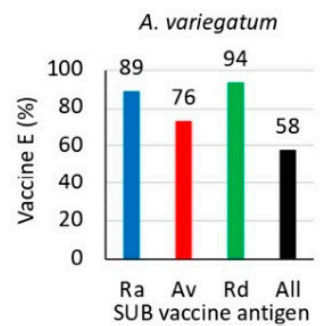

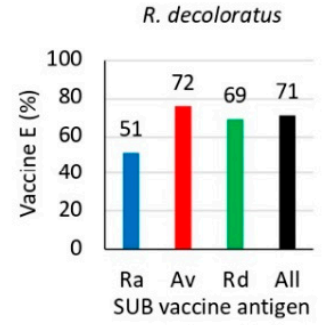

C

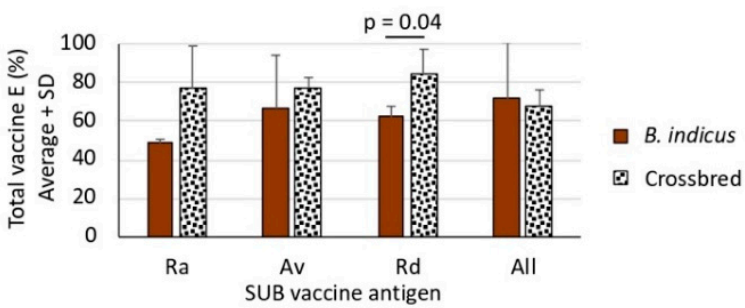

D

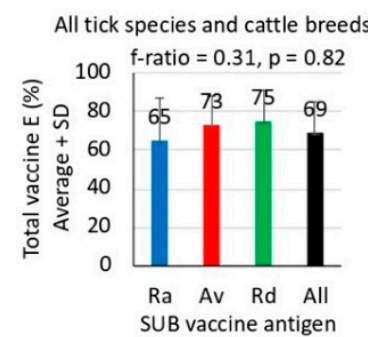

Figure 6. Analysis of vaccine $\mathrm{E}$. Vaccine $\mathrm{E}(\%)$ was calculated as $100(1-(\mathrm{DL} \times \mathrm{DMn} \times \mathrm{DN} \times \mathrm{DMa} \times \mathrm{DA}$ $\times \mathrm{DO} \times \mathrm{DF}$ )), and only parameters with statistically significant differences (Chi-square test; $p<0.05$, $n=4$ biological replicates; Data S1) were included in the analysis. (A) results of the vaccination trials in B. indicus cattle. (B) results of the vaccination trials in crossbred cattle. (C) total vaccine $\mathrm{E}$ for each antigen against all tick species was compared between $B$. indicus and crossbred cattle by a Student's t-test with unequal variance ( $p=0.05 ; n=2-3$, i.e., three tick species in crossbred cattle or two tick species in B. indicus). (D) a Spearman's Rho correlation analysis was performed between total vaccine $\mathrm{E}$ values for each antigen in all cattle breeds and tick species (f-ratio $=0.31, p=0.82 ; n=5$, i.e., three tick species in crossbred cattle plus two tick species in B. indicus).

The IgG antibody response is an important correlate of protection in anti-tick vaccines $[13,28,35,36$, 43-46]. Therefore, to explore this concept herein we conducted correlation analyses between the values of the parameters of Rhipicephalus spp. tick life stages used for the calculation of vaccine $\mathrm{E}$ that showed significant differences with at least three of the SUB vaccine formulations (Figure 6B,C and Table 1) and the anti-R. appendiculatus SUB antibody titers at day 60 before tick challenge (Figure 7A-C). All animals in both vaccinated and control groups were included in the analysis. 
A B. indicus - R. appendiculatus
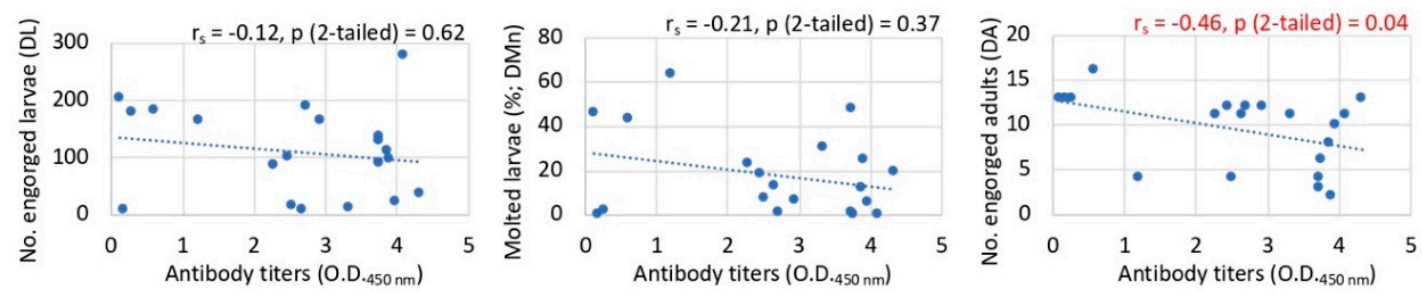

B Crossbred-R. appendiculatus
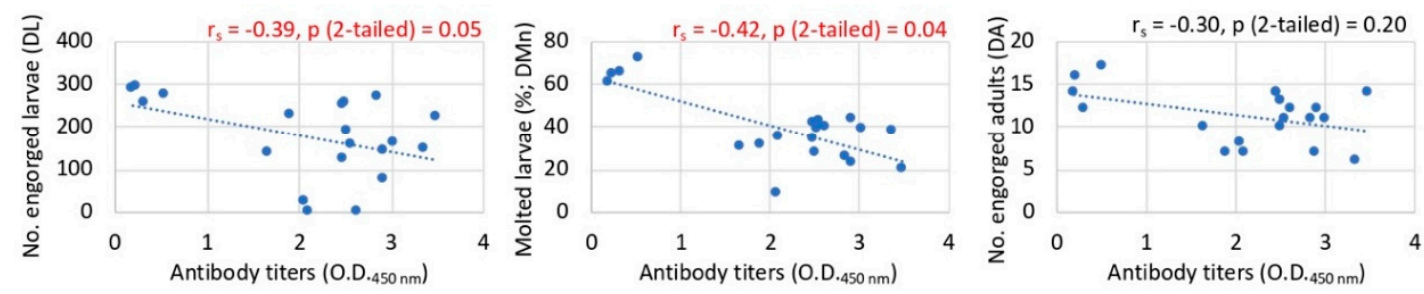

C Crossbred-R. decoloratus
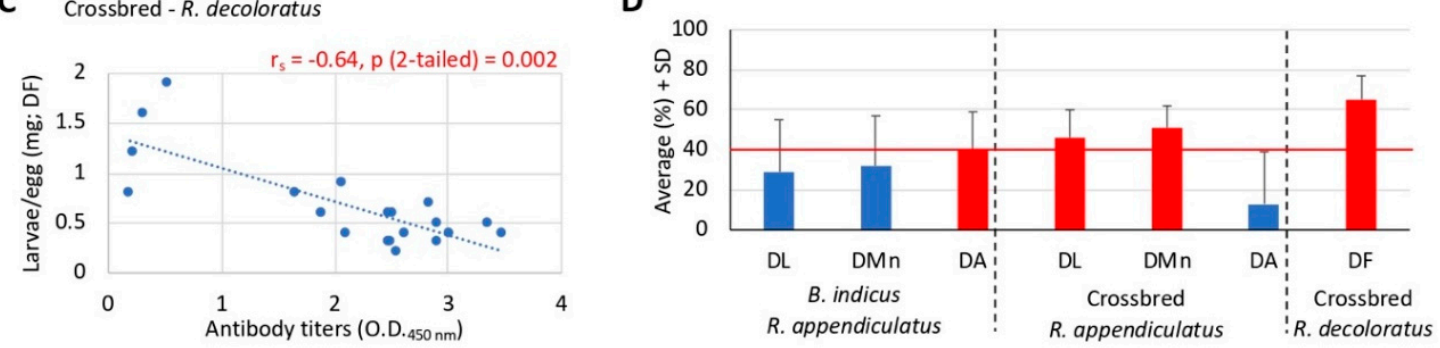

Figure 7. Correlation analysis between anti-SUB antibody titers and vaccination effect on different tick developmental stages. (A) B. indicus cattle infested with R. appendiculatus. (B) crossbred cattle infested with $R$. appendiculatus. (C) crossbred cattle infested with $R$. decoloratus. (D) values (average $+\mathrm{SD}$ ) of the parameters of the tick developmental stages used in the analysis (in red are shown the parameters with significant negative correlation with anti-SUB antibody titers and the threshold value line for observing significant differences). The correlation analyses were conducted between the values of the parameters of Rhipicephalus spp. tick life stages used for the calculation of vaccine E that showed significant differences with at least three of the SUB vaccine formulations (Table 1) and the anti- $R$. appendiculatus SUB antibody titers at day 60 before tick challenge. All animals in both vaccinated and control groups were included in the analysis. Data was analyzed using a Spearman's Rho correlation analysis ( $p \leq 0.05 ; n=20$, i.e., 4 animals for each of the 5 vaccine formulations including the control).

As expected from previous experiments [28,35,36,43-46], a tendency towards a negative correlation between antibody titers and tick life stage parameters was observed (Figure 7A-C). The results showed that for R. appendiculatus ticks, a significant negative correlation $(p \leq 0.05)$ was observed for DA in $B$. indicus (Figure 7A) and for DL and DMn in crossbred cattle (Figure 7B). For R. decoloratus, a significant negative correlation ( $p=0.002$ ) was obtained for DF (Figure 7C). Then, using the average values for the parameters of the tick developmental stages used in the analysis (Figure 7A-C), the results showed that a $40 \%$ reduction was the threshold value for observing a significant negative correlation between antibody titers and tick life stage parameters (Figure 7D).

These results support the possibility of using SUB-based vaccines for the control of multiple tick species in different cattle breeds and a role for the antigen-specific antibody response in the reduction of tick infestations after vaccination with SUB.

\section{Conclusions}

The results of the study provided information on SUB genetic diversity among tick species in Uganda with distinctive amino acids. The antigen-specific IgG antibody response to vaccination with 
SUB was higher throughout the experiment in vaccinated animals than in adjuvant-treated controls. Vaccination with SUB affected various tick developmental stages with minor differences between tick species and a higher vaccine $\mathrm{E}$ in crossbred cattle. Cross-protection between the different SUB antigens was observed, reflecting protein sequence homology between SUB from different tick species. Therefore, the results of vaccine E support the possibility of using SUB antigens for the control of multiple tick species in different cattle breeds. Finally, the negative correlation between anti-SUB antibody titers and tick life stage parameters support a role of the antigen-specific antibody response in the reduction of tick infestations after vaccination with SUB.

These results support the possibility of using SUB antigens for the control of multiple tick species in B. indicus and crossbred cattle in Uganda. Comparing the different SUB antigen vaccine formulations, the results did not support the use of antigen combination. Instead, vaccination with $R$. appendiculatus SUB affected the highest number of developmental stages in all tick species with a high reduction of early developmental stages in three-host ticks. Furthermore, the vaccine with $R$. appendiculatus SUB was the only one showing a higher E against infestations by tick species with the same origin of the antigen. Based on these evidences, we propose to use $R$. appendiculatus SUB to continue research on vaccine design and formulation. Future directions would include quantum vaccinology approaches based on the characterization of the SUB protective epitopes [32] and tick-pathogen interactions [47], modeling of the vaccine $E$ under Ugandan ecological and epidemiological conditions [4] and optimization of vaccine formulation including the possibility of oral administration to improve cattle welfare and safety [34].

Supplementary Materials: The following are available online at http://www.mdpi.com/2076-393X/8/2/319/ s1, Figure S1: Effect of vaccination with SUB on different tick developmental stages, Data S1: Results of the vaccination trials.

Author Contributions: Conceptualization, J.d.1.F., M.C. and F.K.; methodology, J.d.1.F., M.C. and P.D.K.; validation, M.C., and P.D.K.; investigation, M.C., and P.D.K.; data curation, J.d.l.F., M.C. and P.D.K.; writing-original draft preparation, J.d.l.F.; writing-review and editing, J.d.l.F., P.D.K., M.C. and F.K.; supervision, J.d.l.F., M.C., F.K. and S.M.; project administration, J.d.l.F., F.K. and S.M.; funding acquisition, J.d.l.F., F.K. and S.M. All authors have read and agreed to the published version of the manuscript.

Funding: This research was mainly funded by the National Agricultural Research Organization (NARO) of Uganda. The Vice-presidency for International Affairs of Spanish National Research Council (CSIC) of Spain provided additional funds.

Acknowledgments: We thank Ambrose Agona (NARO Director General), Yona Baguma (NARO Deputy Director General Research) and Halid Kirunda (Director Mbarara ZARDI) for their support to this project. We thank members of our laboratories for their contribution and support to this work. We thank Katherine M. Kocan (Oklahoma State University, Stillwater, OK, USA) for tick images displayed in Figure 5.

Conflicts of Interest: The authors declare no conflict of interest.

\section{References}

1. Jongejan, F.; Uilenberg, G. The global importance of ticks. Parasitology 2004, 129, S3-S14. [CrossRef] [PubMed]

2. de la Fuente, J.; Estrada-Peña, A.; Venzal, J.M.; Kocan, K.M.; Sonenshine, D.E. Overview: Ticks as vectors of pathogens that cause disease in humans and animals. Front. Biosci. 2008, 13, 6938-6946. [CrossRef] [PubMed]

3. Muhanguzi, D.; Byaruhanga, J.; Amanyire, W.; Ndekezi, C.; Ochwo, S.; Nkamwesiga, J.; Mwiine, F.N.; Tweyongyere, R.; Fourie, J.; Madder, M.; et al. Invasive cattle ticks in East Africa: Morphological and molecular confirmation of the presence of Rhipicephalus microplus in south-eastern Uganda. Parasites Vectors 2020, 13, 165. [CrossRef] [PubMed]

4. de la Fuente, J.; Contreras, M.; Kasaija, P.D.; Gortazar, C.; Ruiz-Fons, J.F.; Mateo, R.; Kabi, F. Towards a multidisciplinary approach to improve cattle health and production in Uganda. Vaccines 2019, 7, 165. [CrossRef] [PubMed]

5. Mapholi, N.O.; Marufu, M.C.; Maiwashe, A.; Banga, C.B.; Muchenje, V.; MacNeil, M.D.; Chimonyo, M.; Dzama, K. Towards a genomics approach to tick (Acari: Ixodidae) control in cattle: A review. Ticks Tick-Borne Dis. 2014, 5, 475-483. [CrossRef] 
6. de la Fuente, J. Controlling ticks and tick-borne diseases ... looking forward. Ticks Tick-Borne Dis. 2018, 9, 1354-1357. [CrossRef]

7. de la Fuente, J.; Estrada-Peña, A. Why new vaccines for the control of ectoparasite vectors have not been registered and commercialized? Vaccines 2019, 7, 75. [CrossRef]

8. Groot, M.J.; Van't Hooft, K.E. The hidden effects of dairy farming on public and environmental health in the Netherlands, India, Ethiopia, and Uganda, considering the use of antibiotics and other agro-chemicals. Front. Public Health 2016, 4, 12. [CrossRef]

9. de la Fuente, J.; Almazán, C.; Canales, M.; Pérez de la Lastra, J.M.; Kocan, K.M.; Willadsen, P. A ten-year review of commercial vaccine performance for control of tick infestations on cattle. Anim. Health Res. Rev. 2007, 8, 23-28. [CrossRef]

10. Almazán, C.; Tipacamu, G.A.; Rodriguez, S.; Mosqueda, J.; Perez de Leon, A. Immunological control of ticks and tick-borne diseases that impact cattle health and production. Front. Biosci. (Landmark Ed.) 2018, 23, 1535-1551. [CrossRef]

11. Stutzer, C.; Richards, S.A.; Ferreira, M.; Baron, S.; Maritz-Olivier, C. Metazoan parasite vaccines: Present status and future prospects. Front. Cell. Infect. Microbiol. 2018, 8, 67. [CrossRef] [PubMed]

12. Willadsen, P. Vaccination against ectoparasites. Parasitology 2006, 133, S9-S25. [CrossRef] [PubMed]

13. de la Fuente, J.; Contreras, M. Tick vaccines: Current status and future directions. Expert Rev. Vaccines 2015, 14, 1367-1376. [CrossRef] [PubMed]

14. de la Fuente, J.; Kopáček, P.; Lew-Tabor, A.; Maritz-Olivier, C. Strategies for new and improved vaccines against ticks and tick-borne diseases. Parasite Immunol. 2016, 38, 754-769. [CrossRef]

15. Estrada-Peña, A.; Szabó, M.; Labruna, M.; Mosqueda, J.; Merino, O.; Tarragona, E.; Venzal, J.M.; de la Fuente, J. Towards an effective, rational and sustainable approach for the control of cattle ticks in the Neotropics. Vaccines 2020, 8, 9. [CrossRef]

16. Schetters, T.; Bishop, R.; Crampton, M.; Kopáček, P.; Lew-Tabor, A.; Maritz-Olivier, C.; Miller, R.; Mosqueda, J.; Patarroyo, J.; Rodriguez-Valle, M.; et al. Cattle tick vaccine researchers join forces in CATVAC. Parasites Vectors 2016, 9, 105. [CrossRef]

17. Artigas-Jerónimo, S.; Villar, M.; Cabezas-Cruz, A.; Valdés, J.J.; Estrada-Peña, A.; Alberdi, P.; de la Fuente, J. Functional evolution of Subolesin/Akirin. Front. Physiol. 2018, 9, 1612. [CrossRef]

18. Adaszek, L.; Winiarczyk, S. Molecular characterization of Babesia canis canis isolates from naturally infected dogs in Poland. Vet. Parasitol. 2008, 152, 235-241. [CrossRef]

19. Chaligiannis, I.; Fernández de Mera, I.G.; Papa, A.; Sotiraki, S.; de la Fuente, J. Molecular identification of tick-borne pathogens in ticks collected from dogs and small ruminants from Greece. Exp. Appl. Acarol. 2018, 74, 443-453. [CrossRef]

20. Jones, D.T.; Taylor, W.R.; Thornton, J.M. The rapid generation of mutation data matrices from protein sequences. Bioinformatics 1992, 8, 275-282. [CrossRef]

21. Kumar, S.; Stecher, G.; Li, M.; Knyaz, C.; Tamura, K. MEGA X: Molecular Evolutionary Genetics Analysis across computing platforms. Mol. Biol. Evol. 2018, 35, 1547-1549. [CrossRef] [PubMed]

22. Almazán, C.; Moreno-Cantú, O.; Moreno-Cid, J.A.; Galindo, R.C.; Canales, M.; Villar, M.; de la Fuente, J. Control of tick infestations in cattle vaccinated with bacterial membranes containing surface-exposed tick protective antigens. Vaccine 2012, 30, 265-272. [CrossRef]

23. Rodríguez, M.; Massard, C.L.; Henrique da Fonseca, A.; Fonseca Ramos, N.; Machado, H.; Labarta, V.; de la Fuente, J. Effect of vaccination with a recombinant Bm86 antigen preparation on natural infestations of Boophilus microplus in grazing dairy and beef pure and cross-bred cattle in Brazil. Vaccine 1995, 13, 1804-1808. [CrossRef]

24. Aguirre Ade, A.; Garcia, M.V.; Szabó, M.P.; Barros, J.C.; Andreotti, R. Formula to evaluate efficacy of vaccines and systemic substances against three-host ticks. Int. J. Parasitol. 2015, 45, 357-359. [CrossRef] [PubMed]

25. Contreras, M.; Villar, M.; de la Fuente, J. A vaccinomics approach to the identification of tick protective antigens for the control of Ixodes ricinus and Dermacentor reticulatus infestations in companion animals. Front. Physiol. 2019, 10, 977. [CrossRef] [PubMed]

26. Contreras, M.; Moreno-Cid, J.A.; Domingos, A.; Canales, M.; Díez-Delgado, I.; Pérez de la Lastra, J.M.; Sánchez, E.; Merino, O.; López Zavala, R.; Ayllón, N.; et al. Bacterial membranes enhance the immunogenicity and protective capacity of the surface exposed tick Subolesin-Anaplasma marginale MSP1a chimeric antigen. Ticks Tick-Borne Dis. 2015, 6, 820-828. [CrossRef] 
27. de la Fuente, J.; Moreno-Cid, J.A.; Galindo, R.C.; Almazán, C.; Kocan, K.M.; Merino, O.; Pérez de la Lastra, J.M.; Estrada-Peña, A.; Blouin, E.F. Subolesin/Akirin vaccines for the control of arthropod vectors and vector-borne pathogens. Transbound. Emerg. Dis. 2013, 60, 172-178. [CrossRef]

28. Moreno-Cid, J.A.; Pérez de la Lastra, J.M.; Villar, M.; Jiménez, M.; Pinal, R.; Estrada-Peña, A.; Alarcón, P.; Delacour, S.; Oropeza, V.; Ruiz, I.; et al. Control of multiple arthropod vector infestations with subolesin/akirin vaccines. Vaccine 2013, 31, 1187-1196. [CrossRef]

29. Macqueen, D.J.; Johnston, I.A. Evolution of the multifaceted eukaryotic akirin gene family. BMC Evol. Biol. 2009, 9, 34. [CrossRef]

30. Galindo, R.C.; Muñoz, P.M.; de Miguel, M.J.; Marin, C.M.; Blasco, J.M.; Gortazar, C.; Kocan, K.M.; de la Fuente, J. Differential expression of inflammatory and immune response genes in rams experimentally infected with a rough virulent strain of Brucella ovis. Vet. Immunol. Immunopathol. 2009, 127, 295-303. [CrossRef]

31. Sultana, H.; Patel, U.; Sonenshine, D.E.; Neelakanta, G. Identification and comparative analysis of subolesin/akirin ortholog from Ornithodoros turicata ticks. Parasites Vectors 2015, 8, 132. [CrossRef] [PubMed]

32. Artigas-Jerónimo, S.; Pastor Comín, J.J.; Villar, M.; Contreras, M.; Alberdi, P.; León Viera, I.; Soto, L.; Cordero, R.; Valdés, J.J.; Cabezas-Cruz, A.; et al. A novel combined scientific and artistic approach for advanced characterization of interactomes: The Akirin/Subolesin model. Vaccines 2020, 8, 77. [CrossRef] [PubMed]

33. de la Fuente, J.; Moreno-Cid, J.A.; Canales, M.; Villar, M.; Pérez de la Lastra, J.M.; Kocan, K.M.; Galindo, R.C.; Almazán, C.; Blouin, E.F. Targeting arthropod subolesin/akirin for the development of a universal vaccine for control of vector infestations and pathogen transmission. Vet. Parasitol. 2011, 181, 17-22. [CrossRef] [PubMed]

34. Contreras, M.; Kasaija, P.D.; Merino, O.; de la Cruz-Hernandez, N.I.; Gortazar, C.; de la Fuente, J. Oral vaccination with a formulation combining Rhipicephalus microplus Subolesin with heat inactivated Mycobacterium bovis reduces tick infestations in cattle. Front. Cell. Infect. Microbiol. 2019, 9, 45. [CrossRef]

35. Merino, M.; Antunes, S.; Mosqueda, J.; Moreno-Cid, J.A.; Pérez de la Lastra, J.M.; Rosario-Cruz, R.; Rodríguez, S.; Domingos, A.; de la Fuente, J. Vaccination with proteins involved in tick-pathogen interactions reduces vector infestations and pathogen infection. Vaccine 2013, 31, 5889-5896. [CrossRef]

36. Shakya, M.; Kumar, B.; Nagar, G.; de la Fuente, J.; Ghosh, S. Subolesin: A candidate vaccine antigen for the control of cattle tick infestations in Indian situation. Vaccine 2014, 32, 3488-3494. [CrossRef]

37. Slifka, M.K.; Amanna, I. How advances in immunology provide insight into improving vaccine efficacy. Vaccine 2014, 32, 2948-2957. [CrossRef]

38. Yang, D.; Frego, L.; Lasaro, M.; Truncali, K.; Kroe-Barrett, R.; Singh, S. Efficient Qualitative and Quantitative Determination of Antigen-induced Immune Responses. J. Biol. Chem. 2016, 291, 16361-16374. [CrossRef]

39. Prechl, J. A generalized quantitative antibody homeostasis model: Antigen saturation, natural antibodies and a quantitative antibody network. Clin. Transl. Immunol. 2017, 6, e131. [CrossRef]

40. Canales, M.; Enríquez, A.; Ramos, E.; Cabrera, D.; Dandie, H.; Soto, A.; Falcón, V.; Rodríguez, M.; de la Fuente, J. Large-scale production in Pichia pastoris of the recombinant vaccine Gavac against cattle tick. Vaccine 1997, 15, 414-422. [CrossRef]

41. Popara, M.; Villar, M.; Mateos-Hernández, L.; de Mera, I.G.; Marina, A.; del Valle, M.; Almazán, C.; Domingos, A.; de la Fuente, J. Lesser protein degradation machinery correlates with higher BM86 tick vaccine efficacy in Rhipicephalus annulatus when compared to Rhipicephalus microplus. Vaccine 2013, 31, 4728-4735. [CrossRef] [PubMed]

42. Olds, C.L.; Mwaura, S.; Odongo, D.O.; Scoles, G.A.; Bishop, R.; Daubenberger, C. Induction of humoral immune response to multiple recombinant Rhipicephalus appendiculatus antigens and their effect on tick feeding success and pathogen transmission. Parasites Vectors 2016, 9, 484. [CrossRef] [PubMed]

43. Cobon, G.; Hungerford, J.; Woodrow, M.; Smith, D.; Willadsen, P. Vaccination against Boophilus microplus: The Australian field experience. In Recombinant Vaccines for the Control of Cattle Tick; de la Fuente, J., Ed.; Elfos Scientiae: Havana, Cuba, 1995; pp. 163-176.

44. de la Fuente, J.; Rodríguez, M.; Redondo, M.; Montero, C.; García-García, J.C.; Méndez, L.; Serrano, E.; Valdés, M.; Enríquez, A.; Canales, M.; et al. Field studies and cost-effectiveness analysis of vaccination with Gavac $^{\mathrm{TM}}$ against the cattle tick Boophilus microplus. Vaccine 1998, 16, 366-373. [CrossRef] 
45. Contreras, M.; de la Fuente, J. Control of Ixodes ricinus and Dermacentor reticulatus tick infestations in rabbits vaccinated with the Q38 Subolesin/Akirin chimera. Vaccine 2016, 34, 3010-3013. [CrossRef] [PubMed]

46. Ghosh, S.; Singh, N.K.; Das, G. Assessment of duration of immunity in crossbred cattle immunized with glycoproteins isolated from Hyalomma anatolicum anatolicum and Boophilus microplus. Parasitol. Res. 2005, 95, 319-326. [CrossRef]

47. Rego, R.O.M.; Trentelman, J.J.A.; Anguita, J.; Nijhof, A.M.; Sprong, H.; Klempa, B.; Hajdusek, O.; Tomás-Cortázar, J.; Azagi, T.; Strnad, M.; et al. Counterattacking the tick bite: Towards a rational design of anti-tick vaccines targeting pathogen transmission. Parasites Vectors 2019, 12, 229. [CrossRef]

(C) 2020 by the authors. Licensee MDPI, Basel, Switzerland. This article is an open access article distributed under the terms and conditions of the Creative Commons Attribution (CC BY) license (http://creativecommons.org/licenses/by/4.0/). 